which will number a very considerable sprinkling of younger men amongst its members, will accept this brand. new and untried scheme. On the contrary, it is far more probable that the more natural division into three examinations will be accepted. If so, why should the student patronise the Colleges for which he will have no longer any need? It is true that a proviso bas been inserted in the Charter, requiring the graduate of the new University to obtain a licence to practise from some one of the present licensing bodies before the M.D. Albert will be granted him; but, to judge from what occurred in the case of the Victoria University, it is unlikely this proviso will be long insisted on. Even if it should be, the Apothecaries' Hall will find no difficulty in giving a licence to practise, whilst the M.D. and M.S. will be obtainable from the University. I am, Sirs, yours \&c.,

Harley.street, Nov. 17th, 1891.

W. Bruce Clarke.

\section{ON THE SPREAD OF INFLUENZA BY CONTAGION.}

\section{To the Editors of THE LANCET.}

SIRS,-As the influenza appears to be again on the warpath in several places, with its characteristic fatality, the method of assuming its epidemic functions is of considerable interest to the public and the profession at the present moment. If the profession is to cope with it as it should do, it can only be by recognising the fact that it becomes epidemic by contagion, and the theory that it spreads by a miasmatic influence should be buried in oblivion.

I have read with much interest the excellent paper by Dr. Richard Sisley in THE LANCET of this week, and in exemplification of his researches $\Upsilon$ should like to add my own experience of the last two epidemics, for there are few positions held by members of my profession more suitable for obtaining correct information in such a case than that which I have the honour to hold in connexion with Rugby School. During the early days of January, 1890, when the influenza was spreading all over the country, as the boy would be coming from many infected districts, the head master consulted me as to whether the school should reassemble as nsual; and seeing that no end was to be gained by such a prohibition, as the whole country was involved, I advised that no exception should be made, and that the school should fulfil its functions. also arranged with the head master the course to be pursued in the event of a large number falling ill at the same time; for it could not be expected that our ordinary machinery could cope with the whole school becoming sick vogether. In the face of such an unprecedented epidemic throughout the country, frequently prostrating whole establishments within a day or two of each other, I resolved, from the few cases I had then seen, and from what I had cead of the epidemic elsewhere, that the only cautious and afe plan, in dealing with such a large number of young people, would be to assume as a working hypothesis that the influenza was a highly infectious malady, and to act accordingly. Icame to the conclusion-for my ownsatisfaction at first, so that I might at least endeavour to contend with my enemy as soon as he approached-that it assumed its epidemic character from contagion, and that it became so virulent because the season was suitable for the growth and development of the poison, and the soil of the human being was in a fit state for the germs to develop true. I therefore isolated every case as soon as it arose, as carefully as if I had scarlet fever, small-pox, or diphtheria to deal with, in this way. 1. Every case was at once removed to the sanatorium. 2. Every case, however mild, was kept in bed for five days. 3. Every case was kept another five days at the sanatorium in order to recover strength and to get hardened and disinfected by fresh air. (At the first I had not realised the importance of this, and the mildest cases suffered in consequence.) 4. They then returned to school, and other precautions were taken for some days to prevent cold. 5. With this result, that I saw no after.effects. The school assembled on Jan. 17th, 1890. The tirst case occurred on Jan. 23rd, and the last on March $10 \mathrm{th}, 1890$. During these six weeks forty-six cases arose, and amongst these there were two cases of otitis, without suppuration, but with the characteristic watery sanious discharge for a day or two. There were no other complications or sequelæ. At this time there were in the school 414 boarders, so that we had only $10 \cdot 3$ per cent. affected. The epidemic affected the school exceedingly kindly, although it was very rife in the town and neighbourbood at the time. This year I have a severer tale to unfold. The school reassembled on Jan. 22nd, 189l. There was not a case of influenza in the school, either mild or severe, until on March 16 th I had an acute case of pneumonia, and between that date and March 28th there occurred five cases of pneumonia and one of pleurisy, evidently incidental to influenza, al though there were no premonitory symptoms of influenza. The storm raged between March 16 th and July $25 \mathrm{ch}$, with a vacation from April 2nd to May lst, during which time, although the above strict precautions were taken, we had eighty. four cases, one of which commenced with cerebral symptoms and died of cerebro-spinal meningitis in fifty-eight hours. This was the only fatal case in both epidemics. Two of the above cases of pneumonia developed empyema, without prior pleuritic effusion, both of which were drained by removal of portion of rib; in the one the wound was closed in five weeks, in the other a month. There were no sequelæ following the ordinary cases of influenza of any sort or kind-owing, as I believe, to every case being kept in bed for five days, and being taken the greatest care of for five days longer. At the time of this epidemic there were 447 boarders in the school, so that only 19 per cent. suffered during this epidemic. Taking the two epidemics together, $15 \cdot 1$ per cent. were victims. At another large school under my medical care, where the means of isolation were not so perfect, in the 1890 epidemic there was no influenza, while in the 1891 epidemic exactly 50 per cent. were infected. In another school with which I am acquainted, where no isolation was attempted, 94 per cent. were seized with the illness in the first epidemic, and not a case during the second. Moreover, one attack usually protects against a second, for I find that of my total number of cases in the school, $46+84=130$, only four had the illness a second time-that is, about 3 per cent. It should be borne in mind that I am only speaking of what I found, and I should add that my experience only records that of a very healthy district, and amongst well.to-do boys. In my private practice during the first epidemic, if a case occurred in a house where isolation was imperfect, the whole household usually succumbed to it; and, further, many houses in country and town, which were victims during the first epidemic, were free during the second, and those houses which escaped during the first suffered during the second epidemic. I do not believe in the virtues of quinine as a prophylactic; for while many were saturated with it, yet as soon as they came in contact with the poison they became infected with the disease.

It seems to me, therefore, from the above record that we have a contagious disease to deal with, and one that becomes epidemic because of its infectiousness.

I am, Sirs, yours faithfully,

Clement Dukes, M.D., M.R.C.P. Lond., Physician to Rugby School; Sen. Physician

Rugby, Nov. 16th, 1891. to Rugby Hospital.

\section{To the Editors of THE LANCET.}

SIRS, - I have just been reading a very interesting communication upon this subject by Dr. Sisley to the Epidemiological Society. He asks for further information. I should like to supplement his remarks by a reference to the behaviour of somewhat similar diseases in the animal and vegetable kingdoms. I made a very comprehensive study of the potato blight when it inflicted so much damage some eighteen years ago. The disease was propagated by spores. A few of these, transported by any means, gave the disease to the plant on which they fell. This could be clearly traced. If a number of plants showed evidence of their infection, any neighbouring field to the windward would be sure to suffer as soon as the wind was strong enough to carry the spores from the infected to the uninfected plants, provided certain atmospheric conditions were present, such as absence of sunlight with warmth and moisture. This seems to me to correspond precisely with the behaviour of influenza. In the following year or two eczema epizootica (foot-and-mouth disease) appeared very generally over large districts of the country. I studied this malady very carefully, and watched its effects upon some herds of cattle in which I was specially interested. The disease appeared among some animals in Beddington Park. 
These animals had no personal communication with those I was watching, and were separated by the river Wandle and by a low hedge. There was no personal contact between the workmen on the two estates, but the disease showed itself in the animals to which I refer two or three days after its appearance in Beddington Park. There can be no doubt about the contagiousness of foot-and-mouth disease from animal to animal; and the instance $I$ have mentioned, with one or two others of a similar kind brought to my notice by police reports, satisfied me that the disease could be promulgated hy aerial diffusion as well as by personal contact. The same kind of evidence was produced before the Royal Commission upon Infectious Hospitals, of which I was a member, and proved conclusively that smallpox was capable of being aerially diffused for at least a distance of many feet. I commend these observations to the notice of the members of the Epidemiological Society, for I have myself no doubt that all this class of diseases which affect man, the animal and vegetable kingdom alike, follow similar laws, and it seems to me to be a waste of time to argue the question as to whether or not one is contagious and the other infectious.

Croydon, Nov. 16tb, 1891

I am, Sirs, yours faithfully,

AlfRED CarPenter.

\section{To the Editors of THE LANCET.}

SIRs,-I am glad to observe that there is a rapidly growing tendency among practitioners of human medicine to regard influenza as a communicable disease; for when it is regarded in this light, then steps will be taken to prevent its spread, and its malign influence will be greatly ciminished. At times it is nearly as prevalent in horses as in human beings, and for more than a quarter of a century I have considered it, and dealt with it, as an infectious malady, though $I$ do not at all believe in the inter-communicability of influen $z a$ so far as man and the horse are concerned, for there is no evidence sufficiently strong to warrant the supposition. In the second volume of my work on "Veterinary Sanitary Science and Police," published so long ago as 1875, I have devoted a section to the disease as it manifests itself in the equine species, and $I$ have therein stated (p. 13) that "the malady spreads by virtue of its commnnicability; of this there is logical proof, though it has not been experimentally demonstrated"; while the sanitary measures I proposed for its limitation and suppression were based on that conviction. This conviction has been strongly fortified by my additional experience and observation. May I add that in the same work I have treated of tuberculosis in cattle, have looked upon it as an infectious malady, and have prescribed measures for extinguishing it, as well as safeguarding the public health. But this was in the pre-Kochian days, when such views did not receive attention. Koch's discovery of the bacillus of tuberculosis has not enabled me to add to those suppressive and precautionary measures.-I am, Sirs, yours obediently,

Nov. 18th, 1891. George Fleming.

\section{THE APPROACHING ELECTION OF DIRECT REPRESENTATIVES.}

To the Editors of THE LANCET.

SIRS,-As the time for the issue of the voting papers is now rapidly approaching, we ask you to allow us to thank those who have been active in promoting our candidature and the many friends in all parts of the country who have so cordially promised to support us by their votes. It is peculiarly gratifying to us to learn that on all hands our action during the past five years has given satisfaction to those who did us the honour to elect us as their direct representatives, and we take the opportunity now afforded us thus publicly to acknowledge our gratitude and to assure our constituents that at all times, should they renew their confidence in us by re-electing us, we shall consider it our duty to watch over their interests with constant care and attention. As men who have spent long years in the practice of the profession, and whose duties have brought us into intimate connexion with every branch of it, we feel that the requirements of all sections of our fellow-practitioners are thoroughly known to us, and that we are in a position adequately to represent them.

We have but one request to make-that every member of the profession will record bis vote, and thereby show the interest he feels and takes in the great principle of " direct representation." Whether those votes are caso in our favour or against us, we shall at all times remain

Your obedient servants,
C. G. WhEeluHOUSE.
B. W. Foster.
J. G. GLOVER.

\section{To the Editors of THE LANCET.}

SIRS, - I am exceedingly sorry that Dr. Alderson and Mr. George Brown should have imagined that I referred to them in my letter on "Direct Representation" published last week. In the first place, I had written it before the announcement of their candidature; and secondly, I referred to no one person or persons in particular, but to a "type" of men, by whom I am sure both Dr. Alderson and Mr. Brown would, equally with myself, object to be represented on the Council. "I should certainly have imagined that the first line of my letter would have been sufficient to have proved that io was written before any candidates had appeared other than the three present representatives. The moment I heard that Dr. Alderson and Mr. Brown had taken my letter as an attack upon them, I wrote to these gentlemen disclaiming any such intention, and they have courteously accepted my explanation.

Nov. 13th, 1891. I remain, Sirs, yours faithfully,

A. George Bateman.

\section{To the Editors of THE LANCET.}

Sirs,-In your issue of Saturday last, Mr. Wheelhouse refers to a private correspondence which has passed between us, and says that he should very much like me to publish it, but fears I will not care to do so. His fears notwithstanding, I enclose copy of the letters, and request the favour of publication in your next issue. Mr. Wheelhouse states that I expressed a wish that he and Sir B. W. Foster should retire in favour of myself and Dr. Alderson. It will be seen that I said nothing of the kind. I certainly do wish they had left the field clear for general practitioners. In that case, no doubt other candidates from the ranks of general practitioners would have come forward, and probably should have been spared the worry and expense of this contest - I am, Sirs, yours faithfully,

GEORGE BRown, M.R.C.S. Eng. \& L.S.A. Lond.,

Threadneedle-street, E.C., President of General Practitioners' Nov. 11th, 1891 . Alliance.

\section{[Copr.]}

To C. G. Wheelhouse, Esq.

DEAR SrR,-You will have heard probably ere this that it is my in. tention to offer myself as a candidate for a seat on the General Medical Council. I am anxious that you should understand that I am influenced to oppose the re-election of yourself and Sir B. W. Foster solely by the feeling that it is the duty of general practitioners to enter a protest against our direct representatives being drawn from the ranks of consultants or those associated with the governing bodies of medical corporations or teacbing institutions. The seats for direct representatives were given in response to a demand made on behalf of general practitioners, and $I$ regret very much that you and Sir $B$. W. Foster practitioners, and $I$ regret very much that you and Sir B. W. Foster should have taken advantage of the great influence you wielded through the British Medical Association to prevent those seats from being filled by general practitioners. Of course, I do not contest your right to offer yourself for re-election. I may, however, say that it yourself to have left the field clear for general practitioners. Assuring yourself to have left the field clear for general practitioners. Assuring you of my high esteem of your personal qualities and general approval
of the work you have done since you have been a member of the of the work you have done since you have been
Council,
I remain, yours faithfully,
(Signed) (Signed) GEORGE BROWN.

[COPY.]

Cliff Point, Filey, Yorkshire, Oct. 30th, 1891. DEAR Mr. BRown,--Accept my thanks for your letter received by this evening's mail. I had, of course, heard of your intention and of Dr. Alderson's to become candidates at the coming election, and I can, equally of course, have no objection to your doing so. There is only
one point in your letter which needs any explanation-viz., your assumpone point in your letter which needs any explanation-viz., your assump. tion that I am not a general practitioner, and that I am not in a position. and by night, in medicine, surgery, and midwifery, for thirty years, in and of night, in medicine, surgery, and midwifery, for thirty years, in constitutes "general practice," I can at any rate, claim that; and I do. not see that because, after such an experience as that, my fellow pracnot see that because, after such an experience as that, my fellow pracan experience as that-was worth asking in consultation, that makes me less of a general practitioner than I ever was. Anyway, I feel that if $I$ do not know the needs and requirements of general practitioners no one can ever hope to do so ; and, with this knowledge, I am content once more to seek to represent them in the Council. I have old pupilsscattered over the length and breadth of the land who know me and my career better than you seem to do, and I am quite content to leave my cause in their hands. You have a perfect right to try to wrest my 